\title{
Optimal rehabilitation and community integration for family caregivers of stroke patients
}

\author{
Vivian WQ Lou, MEd (Psychology), MSW, PhD \\ Sau Po Centre on Ageing, Department of Social Work \& Social Administration, The University of Hong Kong
}

Stroke is the second most common cause of disability-adjusted life years worldwide, and the incidence of stroke is highest in east Asia. ${ }^{1}$ In Hong Kong, every year approximately 22,000 people who suffer from stroke are discharged to home or institutional care. ${ }^{2}$ Risk factors for stroke are mainly associated with three aspects, including factors such as high systolic blood pressure and high level of cholesterol; behavioural factors such as smoking, physical inactivity, and diet; and environmental factors such as air pollution. Stroke survivors have three silent needs during rehabilitation: (1) need for rehabilitation of physical, cognitive, psychological and social functions, (2) need to regain an active lifestyle corresponding to their physical and/or mental limitations, and (3) need for environmental adaptation to regain an active lifestyle in a safe, accessible, and empowering environment. ${ }^{3}$

Stroke most often occurs without warning. Both stroke patients and their family caregivers are under enormous stress associated with an uncertain and long-standing future burden brought on by the care needs of stroke survivors. Although the specific needs of stroke survivors and their family caregivers differ according to the level of impairment of the stroke survivor, family caregivers often have a common set of needs, including health information, professional support, and a community network. ${ }^{4}$ In Hong Kong, stroke rehabilitation support services are provided at the hospital setting ${ }^{5}$ (eg, inpatient and outpatient rehabilitation services) and the community setting ${ }^{6}$ (eg, community rehabilitation day centres or self-help groups). However, the existing service scope is mainly patient-focused, and the needs of family caregivers are often neglected.

Under the initiative of Sau Po Centre on Ageing, theWeRISE project ${ }^{7,8}$ aims to empower optimal rehabilitation and social integration for stroke families through health and social care collaboration. The WeRISE project considers that each family has the potential to regain function if timely and effective support can be provided. Since 2016, the WeRISE project has implemented a care management model led by trained social worker care managers and supported by volunteers. The WeRISE project enables a win-win-win situation. Stroke patients and families can achieve better health and well-being outcomes; community can have enhanced social capital for mutual support; and society can be less burdened on health and long-term care.

\section{DECLARATION}

Vivian WQ Lou is the principle investigator of the WeRISE project.

\section{REFERENCES}

1. Gorelick PB. The global burden of stroke: persistent and disabling. Lancet Neurol 2019;18:417-8. Crossref

2. Cerebrovascular Diseases. Department of Health, Government of Hong Kong SAR, 2017. Available from: http://www.healthyhk.gov.hk/ phisweb/en/healthy_facts/disease_burden/major_causes_death/cere_diseases/. Accessed 16 June 2019.

3. Krishnan S, Pappadis MR, Weller SC, Stearnes M, Kumar A, Ottenbacher KJ, et al. Needs of stroke survivors as perceived by their caregivers: a scoping review. Am J Phys Med Rehabil 2017;96:487-505. Crossref

4. Tsai PC, Yip PK, Tai JJ, Lou MF. Needs of family caregivers of stroke patients: a longitudinal study of caregivers' perspectives. Patient Prefer Adherence 2015;9:449-57. Crossref

5. Strategic Service Framework for Rehabilitation Services. Hospital Authority, Government of Hong Kong SAR, 2016. Available from: http:// www.ha.org.hk/haho/ho/ap/HA-RehabSSF-01.pdf. Accessed 16 June 2019.

6. Community Support Services. Social Welfare Department, Government of Hong Kong SAR, 2019; https://www.swd.gov.hk/en/index/site_ pubsvc/page_rehab/sub_listofserv/id_supportcom/. Accessed 16 June 2019.

7. Wong OK, Lo T, Lum TYS, Tang JYM, Lau GKK, Fong K, et al. Healthy and productive ageing: senior volunteerism to empower caregivers of stroke survivors. 12th International Symposium on Healthy Ageing - Wellness and Longevity From Science to Service. Hong Kong: March 11-12, 2017.

8. Lou VWQ, Fu JYQ, Tang JYM, Lum TYS, Lau GKK, Fong K, et al. Development and validation of a two-tier management model for stroke caregivers: a randomized controlled trial. Hospital Authority Convention. Hong Kong: May 7-8, 2018. 